\title{
FONTES DE RESISTÊNCIA À MURCHA-DE-CURTOBACTERIUM EM CULTIVARES LOCAIS DE FEIJOEIRO, COLETADAS EM SANTA CATARINA
}

\author{
Identification of resistance sources of bacterial wilt in common \\ bean landraces, collected in Santa Catarina
}

\author{
Gustavo de Faria Theodoro ${ }^{1}$, Daniel Henrique Herbes ${ }^{2}$, Antonio Carlos Maringoni
}

\begin{abstract}
RESUMO
Avaliou-se a reação de 73 cultivares locais de feijoeiro, coletadas em Santa Catarina, à murcha-de-curtobacterium, causada por Curtobacterium flaccumfaciens pv. flaccumfaciens. Os experimentos foram instalados em condições de casa-de-vegetação e as cultivares IAC Carioca Pyatã e IPR 88 - Uirapuru foram os padrões resistente e suscetível, respectivamente. Aos 10 dias após a emergência, houve a inoculação das plantas com o isolado FJ 36 e as avaliações dos sintomas ocorreram aos 10, 14, 21 e 28 dias após a inoculação. Foi possível identificar as cv. locais Mouro Piratuba (grupo de coloração variada) e Vagem Amarela (grupo preto) como fontes de resistência à murcha-de-curtobacterium.
\end{abstract}

Termos para indexação: Phaseolus vulgaris, resistência genética, controle, Curtobacterium flaccumfaciens pv. flaccumfaciens.

\begin{abstract}
It was evaluated the reaction of 73 common bean land races, collected in Santa Catarina State, to the bacterial wilt, caused by Curtobacterium flaccumfaciens pv.flaccumfaciens. The experiments were set up under greenhouse conditions and the cultivars IAC Carioca Pyatã and IPR 88 - Uirapuru were the resistant and susceptible standards, respectively. The inoculation with the strain FJ 36 was done in the $10^{\text {th }}$ day after the sowing and the disease evaluations were at the $10,14,21$ and $28^{\text {th }}$ day after the inoculation. The landraces Mouro Piratuba (color bean group) and Vagem Amarela (black bean group) were identified as resistance sources of bacterial wilt of bean.
\end{abstract}

Index terms: Phaseolus vulgaris, genetic resistance, control, Curtobacterium flaccumfaciens pv.flaccumfaciens.

(Recebido em 27 de junho de 2006 e aprovado em 7 de maio de 2007)

\section{INTRODUÇÃO}

O feijoeiro possui relevante importância em Santa Catarina, especialmente para os pequenos agricultores que empregam mão-de-obra de origem familiar e utilizam seus grãos como fonte de proteínas na alimentação. Na safra 2005, o Estado de Santa Catarina ocupou o oitavo lugar no ranking dos estados que se destacaram na produção de feijão, com cerca de 110 mil toneladas de grãos, em uma área cultivada de 114,5 mil hectares e rendimento médio de 961,1 kg.ha-1 (FREYESLEBEN, 2005). Porém, a redução da área cultivada com feijoeiro no território catarinense, nos últimos anos, tem sido o reflexo da instabilidade do mercado, intempéries climáticas e a produção de grãos de baixa qualidade comercial, por conseqüência da reduzida ou ausente utilização de tecnologia (FLESCH, 2003).

A murcha-de-curtobacterium, causada por Curtobacterium flaccumfaciens pv. flaccumfaciens (Hedges) Collins \& Jones, tem se tornado uma ameaça no Brasil. Essa doença foi primeiramente constatada no Estado de São Paulo e, atualmente, é encontrada no Distrito
Federal e nos estados de Goiás e Paraná (LEITE JÚNIOR et al., 2001; MARINGONI \& ROSA, 1997; UESUGI et al., 2003). Em Santa Catarina, foi relatada por Leite Júnior et al. (2001) no município de Campos Novos e, posteriormente, em Faxinal dos Guedes, Guatambu, Ipuaçu, Ponte Serrada e Tigrinhos por Theodoro \& Maringoni (2006a), indicando a adaptabilidade do patógeno ao hospedeiro e aos dois subtipos climáticos de Köppen presentes em Santa Catarina (Cfa e Cfb). Acredita-se que essa doença possa estar em outros municípios catarinenses.

O controle da murcha-de-curtobacterium do feijoeiro está fundamentado no uso de sementes sadias, rotação de culturas e cultivares resistentes (HALL, 1991). A quantidade de nutrientes fornecida pela adubação deve ser de acordo com o indicado pela análise de solo, principalmente para evitar o fornecimento excessivo de nitrogênio (THEODORO \& MARINGONI, 2006b,c). Todas as cultivares atualmente recomendadas para Santa Catarina mostraram-se suscetíveis a $C$. $f$. pv. flaccumfaciens (THEODORO \& MARINGONI, 2006a).

\footnotetext{
'Engenheiro Agrônomo, Doutor, Professor Adjunto - Câmpus de Chapadão do Sul/CPCS - Universidade Federal de Mato Grosso do Sul/UFMS Cx. P. 112 - 79560-000 - Chapadão do Sul, MS - theodoro@nin.ufms.br ${ }^{2}$ Graduando em Agronomia - Universidade Comunitária Regional de Chapecó/UNOCHAPECÓ - Avenida Sen. Atílio Fontana, 591-E - Cx. P. 747 89809-000 - Chapecó, SC - dhh@unochapeco.edu.br

${ }^{3}$ Engenheiro Agrônomo, Doutor - Departamento de Produção Vegetal, Setor de Defesa Fitossanitária - Faculdade de Ciências Agronômicas/FCA Universidade Estadual Paulista/UNESP - Cx. P. 237 - 18603-970 - Botucatu, SP - maringoni@fca.unesp.br
} 
As cultivares locais são identificadas pela sua adaptabilidade regional, por estarem presentes na maioria dos pequenos estabelecimentos rurais que empregam mão-de-obra familiar, apresentarem grande variabilidade genética e até mesmo genes de resistência a doenças. Rodrigues et al. (2002) observaram que as cultivares locais de feijoeiro, empregadas no Rio Grande do Sul, apresentaram variabilidade genética superior àquelas encontradas em cultivares oriundas da pesquisa, indicando a importância de sua inclusão em programas de melhoramento genético. Theodoro (2004) identificou fontes de resistência ao crestamento bacteriano comum, causado por Xanthomonas axonopodis pv. phaseoli, em cultivares locais de feijoeiro, coletadas em Santa Catarina. Avaliando cultivares locais coletadas em diversas regiões brasileiras, Rava et al. (2003) constataram que as cultivares locais de feijoeiro CF 800375, Coquinho Enxofre, Feijão Baetão, Mulatinho MG e Vermelho 1 Epamig foram resistentes ao isolado Cff CNF 04, de C.f. pv.flaccumfaciens.

Objetivou-se neste trabalho, avaliar a reação de cultivares locais de feijoeiro, coletadas no Estado de Santa Catarina, à murcha-de-curtobacterium, visando identificar fontes de resistência a essa doença.

\section{MATERIAL E MÉTODOS}

Conduziram-se quatro ensaios, em condições de casa-de-vegetação, para avaliar a reação de cultivares locais de feijoeiro, coletadas no Estado de Santa Catarina, à murcha-de-curtobacterium. Foram avaliadas 73 cultivares locais, com grãos dos grupos preto $(54,1 \%)$, de coloração variada $(35,1 \%)$ e carioca $(10,8 \%)$ e uma linhagem de feijoeiro (CHC 99-137).

As sementes foram imersas em solução contendo benomyl a $0,25 \mathrm{~g} . \mathrm{L}^{-1}$, durante cinco minutos e colocadas para pré-germinar em papel toalha umedecido a $\pm 25^{\circ} \mathrm{C}$, até a emissão da radícula. Cinco sementes pré-germinadas foram transferidas para sacos plásticos, com $8 \mathrm{~L}$ de solo de lavoura com a acidez corrigida e adubado segundo a análise de solo. Realizou-se o desbaste, uma semana após o plantio, mantendo-se três plantas por saco plástico. Procedeu-se à inoculação das plantas, com o isolado FJ 36, de C. $f$. pv. flaccumfaciens, aos dez dias após a emergência e por meio de picadas no epicótilo das plantas com uma alça reta previamente umedecida em colônias bacterianas, cultivadas a $28^{\circ} \mathrm{C}$, por $96 \mathrm{~h}$, em placa de Petri contendo o meio de cultura nutriente-sacarose-ágar (extrato de carne $-3,0 \mathrm{~g}$, peptona - 5,0 g, ágar - 15,0 g, sacarose 5,0 g, água destilada q.s.p. $-1000 \mathrm{~mL}$ ), de acordo com a metodologia empregada por Maringoni (2002). O tratamento testemunha foi representado pelo uso de água destilada, ao invés de inóculo, nas picadas em plantas da cultivar IPR 88 - Uirapuru.

Empregou-se o delineamento experimental blocos ao acaso, com quatro repetições, e cada parcela experimental foi representada por um saco plástico contendo três plantas. A avaliação dos sintomas ocorreu aos 10, 14, 21 e 28 dias após a inoculação (DAI), empregando-se a escala descritiva adaptada por Maringoni (2002): 0 = sem sintomas de doença; 1 = sintoma de mosaico nas folhas; 2 = poucas folhas murchas ( 1 a 3 folhas, menos de $10 \%$ das folhas das plantas); 5 = aproximadamente $25 \%$ de folhas apresentando murcha e amarelecimento; $7=$ aproximadamente $50 \%$ de folhas murchas, amarelecimento e necrose de folíolos, plantas com nanismo; $9=$ aproximadamente $75 \%$ ou mais de folhas com murcha e/ou necrose, queda prematura de folhas, nanismo severo e ou morte da planta. As reações de resistência e de suscetibilidade foram consideradas, para notas médias de severidade, até dois e superiores a 2,1, respectivamente. A partir dos valores de severidade obtidos, foi estimada a área abaixo da curva de progresso da murcha-decurtobacterium em cada genótipo, de acordo com a fórmula:

$$
\mathrm{AACPMC}=\left\{[(\mathrm{Y} 1+\mathrm{Y} 2) / 2]^{*} \mathrm{t}\right\}
$$

onde: $\mathrm{Y}_{1}$ e $\mathrm{Y}_{2}$ corresponderam aos valores de severidade para duas avaliações sucessivas dentro do mesmo bloco e Dt, o intervalo de tempo entre elas. Os valores de AACPMC foram submetidos à análise de comparação entre médias pelo teste de Tukey, a 5\% de probabilidade. O controle das pragas que ocorreram nos ensaios foi feito por meio de pulverizações com produtos registrados para a cultura.

\section{RESULTADOS E DISCUSSÃO}

Os resultados referentes à reação de cultivares locais de feijoeiro encontram-se nas Tabelas 1 a 4 . Durante a condução dos ensaios, a temperatura esteve elevada no interior da casa-de-vegetação e favoreceu a expressão dos sintomas da doença nas cultivares inoculadas.

No primeiro ensaio (Tabela 1), aos 10 DAI, verificouse que apenas as cultivares Azulão Arredondado, Preto Alongado, Vermelho Alongado, Vermelho Comprido e Vermelho Rosado tiveram nota média de severidade abaixo de 2,0 (Tabela 1). A 'Azulão Redondo' foi a única cultivar local resistente aos $14 \mathrm{DAI}$, exibindo um maior período de incubação da doença. Porém, embora este genótipo tenha apresentado uma AACPMC semelhante $(\mathrm{P}<0,05)$ àquela da cultivar IAC Carioca Pyatã (padrão resistente), foi 
considerada suscetível por apresentar nota média de severidade igual a 4,50, na última avaliação.

No segundo ensaio (Tabela 2), as cultivares Mourão, Enxofre Pequeno, Enxofre e IPR 88 - Uirapuru (padrão suscetível) apresentaram nota média de severidade superior a 2,1 aos 10 DAI, indicando elevada suscetibilidade à murcha-de-curtobacterium (Tabela 2). 'Mouro Piratuba', 'Preto Brilhoso Achatado', 'Preto Chatinho', 'Preto Brilhoso', 'Preto Brilhoso Manteiga' e 'Tipo Irai' permaneceram resistentes aos 14 DAI. Houve intensa desfolha na cultivar Enxofre Pequeno, aos 28 DAI.

Já no terceiro ensaio (Tabela 3), somente as cultivares locais Guarapuava, Azul Linha Tafona, FC 2061, FC 2045 e Tipo IAPAR 31 mostraram severidade média abaixo de 2,1 aos 10 DAI e, logo aos 14 DAI, nenhuma dessas permaneceu resistente ao isolado FJ 36. No quarto ensaio, também somente foram observadas cultivares locais resistentes aos 10 DAI, com exceção da 'Vagem Amarela', que permaneceu com nota média de severidade de 1,33 até os 28 DAI (Tabela 4).

TABELA 1 - Comportamento de cultivares locais de feijoeiro ao isolado FJ 36, de Curtobacterium flaccumfaciens pv. flaccumfaciens (Ensaio 1). Epagri/Cepaf, Chapecó, SC, 2005.

\begin{tabular}{|c|c|c|c|c|c|c|}
\hline \multirow[b]{2}{*}{ Cultivares } & \multicolumn{4}{|c|}{ Severidade médiaa $^{1}$} & \multirow[b]{2}{*}{ Reação $^{3}$} & \multirow[b]{2}{*}{ AACPMC $^{4}$} \\
\hline & $10 \mathrm{DAI}^{2}$ & 14 DAI & 21 DAI & 28 DAI & & \\
\hline Avermelhado Malhado & 7,08 & 8,25 & 9,00 & 9,00 & $\mathrm{~S}$ & $154,04 \mathrm{a}$ \\
\hline Preto Opaco (FC 2028) & 6,83 & 8,33 & 8,83 & 9,00 & $S$ & $152,83 \mathrm{a}$ \\
\hline Preto Opaco (FC 2044) & 5,83 & 9,00 & 9,00 & 8,83 & $S$ & $155,08 \mathrm{a}$ \\
\hline Vermelho Rajado (FC 2037) & 5,08 & 8,83 & 9,00 & 9,00 & $S$ & $153,25 \mathrm{a}$ \\
\hline Vermelho Rajado (FC 2057) & 8,17 & 9,00 & 9,00 & 9,00 & $S$ & $160,34 \mathrm{a}$ \\
\hline Vermelho Redondo (FC 2035) & 7,67 & 7,92 & 8,25 & 8,67 & $S$ & 146,96 a \\
\hline IPR 88 - Uirapuru & 4,92 & 7,50 & 9,00 & 9,00 & $S$ & $145,58 \mathrm{ab}$ \\
\hline Preto Brilhoso (FC 2036) & 5,00 & 8,00 & 8,50 & 8,83 & $S$ & $144,42 \mathrm{ab}$ \\
\hline Claro Brilhoso & 2,25 & 7,34 & 8,67 & 7,83 & $S$ & $132,91 \mathrm{abc}$ \\
\hline Preto Opaco (FC 2053) & 5,42 & 8,00 & 8,17 & 8,33 & $S$ & $141,16 \mathrm{abc}$ \\
\hline Preto Precoce & 3,00 & 5,84 & 7,33 & 9,00 & $S$ & $120,92 \mathrm{abc}$ \\
\hline Vermelho Alongado & 1,25 & 4,58 & 8,25 & 8,83 & $S$ & $116,37 \mathrm{abc}$ \\
\hline Vermelho Comprido & 0,34 & 4,83 & 8,33 & 8,83 & $S$ & $116,48 \mathrm{abc}$ \\
\hline Vermelho Redondo (FC 2015) & 3,92 & 7,17 & 8,83 & 8,50 & $S$ & $138,84 \mathrm{abc}$ \\
\hline Preto Alongado & 0,34 & 3,17 & 8,50 & 7,00 & $S$ & $102,09 \mathrm{bc}$ \\
\hline Azulão Arredondado & 0,67 & 2,17 & 8,67 & 6,58 & $S$ & $96,95 \mathrm{c}$ \\
\hline Vermelho Rosado & 1,17 & 2,59 & 8,33 & 7,00 & $S$ & $99,37 \mathrm{c}$ \\
\hline Azulão Redondo & 0,00 & 0,42 & 2,91 & 4,50 & $S$ & $38,41 \mathrm{~d}$ \\
\hline IAC Carioca Pyatã & 0,00 & 0,00 & 0,83 & 0,67 & $\mathrm{R}$ & $8,14 \mathrm{~d}$ \\
\hline IPR 88 - Uirapuru (Testemunha) & 0,00 & 0,00 & 0,00 & 0,00 & - & $0,00^{*}$ \\
\hline $\mathrm{CV}(\%)$ & & & & & & 14,04 \\
\hline
\end{tabular}

${ }^{1}$ Média de quatro repetições; escala de notas de 0 a 9; ${ }^{2}$ Dias após a inoculação; ${ }^{3}$ Reação, aos 28 DAI: suscetibilidade (S) ou resistência (R) ${ }^{4}$ Área abaixo da curva do progresso da murcha-de-curtobacterium. Médias seguidas da mesma letra não diferem ente si na vertical, a 5\% de probabilidade, pelo teste de Tukey. *Dados não incluídos na análise estatística. 
TABELA 2 - Comportamento de cultivares locais de feijoeiro ao isolado FJ 36, de Curtobacterium flaccumfaciens pv. flaccumfaciens (Ensaio 2). Epagri/Cepaf, Chapecó, SC, 2005.

\begin{tabular}{lccccccc}
\hline & \multicolumn{3}{c}{ Severidade média $^{1}$} & & \\
\cline { 2 - 5 } Cultivares & 10 DAI & 14 DAI & 21 DAI & 28 DAI & Reação $^{3}$ & AACPMC $^{4}$ \\
\hline Carioca Precoce & 2,08 & 8,08 & 9,00 & 9,00 & $\mathrm{~S}$ & $143,12 \mathrm{a}$ \\
Enxofre Pequeno & 4,58 & 9,00 & 9,00 & 9,00 & $\mathrm{~S}$ & $153,17 \mathrm{a}$ \\
IPR 88 - Uirapuru & 2,67 & 8,67 & 8,67 & 8,67 & $\mathrm{~S}$ & $143,98 \mathrm{a}$ \\
Mourão & 6,17 & 8,08 & 8,42 & 9,00 & $\mathrm{~S}$ & $147,19 \mathrm{a}$ \\
Enxofre & 4,58 & 5,75 & 9,00 & 8,67 & $\mathrm{~S}$ & $134,11 \mathrm{ab}$ \\
Preto Brilhoso Achatado & 0,17 & 2,08 & 9,00 & 8,67 & $\mathrm{~S}$ & $105,12 \mathrm{bc}$ \\
Preto Redondo & 0,75 & 2,25 & 9,00 & 7,33 & $\mathrm{~S}$ & $102,55 \mathrm{bc}$ \\
Tipo Irai & 0,34 & 2,09 & 7,83 & 8,83 & $\mathrm{~S}$ & $97,88 \mathrm{bc}$ \\
Preto Brilhoso (Cfe 26) & 0,59 & 1,67 & 6,00 & 7,08 & $\mathrm{~S}$ & $77,10 \mathrm{~cd}$ \\
Preto Brilhoso Manteiga & 0,17 & 0,17 & 9,00 & 8,00 & $\mathrm{~S}$ & $92,25 \mathrm{~cd}$ \\
Preto Chatinho & 0,50 & 0,75 & 6,75 & 8,42 & $\mathrm{~S}$ & $81,82 \mathrm{~cd}$ \\
CHC 99-137 & 1,17 & 2,67 & 3,66 & 3,50 & $\mathrm{~S}$ & $54,88 \mathrm{~d}$ \\
IAC Carioca Pyatã & 0,00 & 0,00 & 1,00 & 0,25 & $\mathrm{R}$ & $7,87 \mathrm{e}$ \\
Mouro Piratuba & $\mathbf{0 , 3 4}$ & $\mathbf{0 , 1 7}$ & $\mathbf{0 , 9 2}$ & $\mathbf{0 , 4 2}$ & $\mathbf{R}$ & $\mathbf{9 , 4 5} \mathbf{e}$ \\
IPR 88 - Uirapuru (Testemunha) & 0,00 & 0,00 & 0,00 & 0,00 & - & $0,00^{*}$ \\
\hline CV (\%) & & & & & 15,59
\end{tabular}

CV $(\%) \quad 15,59$

${ }^{1}$ Média de quatro repetições; escala de notas de 0 a 9; ${ }^{2}$ Dias após a inoculação; ${ }^{3}$ Reação, aos 28 DAI: suscetibilidade (S) ou resistência (R) ${ }^{4}$ Área abaixo da curva do progresso da murcha-de-curtobacterium. Médias seguidas da mesma letra não diferem ente si na vertical, a $5 \%$ de probabilidade, pelo teste de Tukey. *Dados não incluídos na análise estatística.

Aos 21 DAI, todas as cultivares locais suscetíveis tiveram nota média de severidade acima de dois, mesmo aquelas que se mostraram "resistentes" até os 14 DAI. Esse resultado corrobora com Theodoro \& Maringoni (2006a), que indicaram que avaliações precoces podem mascarar o comportamento de genótipos perante $C . f$. pv. flaccumfaciens e que o período para proceder às avaliações da murcha-de-curtobacterium em genótipos de feijoeiro deve estender-se, pelo menos, até os 20 DAI. A testemunha não inoculada não manifestou sintomas da doença, enquanto que o padrão de resistência 'IAC Carioca Pyatã' manteve-se com nota média de severidade abaixo de 2,0 até o final das avaliações, aos $28 \mathrm{DAI}$, em todos os ensaios.

Verificou-se que plantas de uma mesma cultivar não reagiram semelhantemente entre si, quando inoculadas com o isolado FJ 36, notando-se feijoeiros com poucos sintomas sendo cultivados no mesmo saco plástico em que plantas mortas por $C$. $f$. pv. flaccumfaciens estiveram presentes. Isto ocorreu com os genótipos Azulão Redondo, CHC 99-137 e Preto Redondo. Sabe-se que cultivares locais são misturas de genótipos, que foram coletados e agrupados por possuírem alguma(s) característica(s) em comum como, por exemplo, a coloração dos grãos. Sugerese a condução de trabalhos visando à seleção de linhagens puras de feijoeiro, a partir das sementes de plantas resistentes à murcha-de-curtobacterium.

Notou-se que, no período entre as últimas avaliações, a linhagem CHC 99-137 e as cultivares locais Enxofre, Tipo Iraí, Mouro Piratuba, Preto Brilhoso Achatado, Preto Brilhoso Manteiga, Preto Redondo, Vermelho Rosado, Preto Alongado, Vermelho Redondo (FC 2015), Preto Opaco (FC 2044), Azulão Arredondado, Claro 
TABELA 3 - Comportamento de cultivares locais de feijoeiro ao isolado FJ 36, de Curtobacterium flaccumfaciens pv. flaccumfaciens (Ensaio 3). Epagri/Cepaf, Chapecó, SC, 2005.

\begin{tabular}{|c|c|c|c|c|c|c|}
\hline \multirow[b]{2}{*}{ Cultivares } & \multicolumn{4}{|c|}{ Severidade média $^{1}$} & \multirow[b]{2}{*}{ Reação $^{3}$} & \multirow[b]{2}{*}{ AACPMC $^{4}$} \\
\hline & $10 \mathrm{DAI}^{2}$ & 14 DAI & 21 DAI & 28 DAI & & \\
\hline FC 2003 & 4,08 & 8,50 & 9,00 & 9,00 & S & $149,42 \mathrm{a}$ \\
\hline FC 2046 & 4,88 & 8,50 & 8,67 & 8,83 & $S$ & $148,08 \mathrm{ab}$ \\
\hline Azul Feira Chapecó & 3,25 & 8,50 & 9,00 & 9,00 & $S$ & $147,75 \mathrm{ab}$ \\
\hline FC 2007 & 4,42 & 7,58 & 8,67 & 9,00 & S & $142,71 \mathrm{ab}$ \\
\hline Carioca & 4,83 & 7,33 & 8,17 & 9,00 & $S$ & $138,67 \mathrm{ab}$ \\
\hline Guarapuava & 2,00 & 7,58 & 8,33 & 9,00 & $S$ & $135,54 \mathrm{ab}$ \\
\hline Feijão Preto & 5,17 & 6,42 & 8,50 & 8,67 & $\mathrm{~S}$ & $135,46 \mathrm{ab}$ \\
\hline Carioca Santiago do Sul & 4,75 & 6,50 & 8,33 & 8,50 & $S$ & $133,34 \mathrm{abc}$ \\
\hline Rio Bonito & 3,75 & 6,75 & 7,83 & 8,83 & $S$ & $130,38 \mathrm{abc}$ \\
\hline FC 2005 & 3,25 & 6,83 & 7,83 & 8,83 & $S$ & $129,84 \mathrm{abc}$ \\
\hline Mourão Canguçu & 4,17 & 6,58 & 7,83 & 8,67 & $S$ & $129,71 \mathrm{abc}$ \\
\hline IPR 88 - Uirapuru & 3,67 & 6,08 & 8,17 & 8,83 & $S$ & $128,87 \mathrm{abc}$ \\
\hline Azul Linha Tafona & 1,25 & 6,17 & 8,50 & 9,00 & $S$ & $127,42 \mathrm{abc}$ \\
\hline Guaramirim & 2,75 & 7,83 & 7,50 & 7,33 & $S$ & $126,75 \mathrm{abc}$ \\
\hline Mourinho Canguçu & 3,00 & 5,25 & 8,33 & 8,83 & $S$ & $124,13 \mathrm{abc}$ \\
\hline Cariocão Palmitos & 2,67 & 5,75 & 7,58 & 8,83 & $S$ & $120,96 \mathrm{abcd}$ \\
\hline FC 2017 & 2,92 & 5,25 & 7,42 & 9,00 & $S$ & $118,13 \mathrm{abcd}$ \\
\hline Azulão Ponte Serrada & 2,08 & 6,50 & 7,25 & 7,67 & $S$ & $117,50 \mathrm{abcd}$ \\
\hline FC 2031 & 2,50 & 7,08 & 6,83 & 7,08 & $S$ & $116,58 \mathrm{abcd}$ \\
\hline FC 2062 & 3,50 & 4,67 & 7,50 & 8,33 & $S$ & $114,34 \mathrm{abcd}$ \\
\hline Vagem Rosca Brilhante & 3,00 & 6,00 & 6,25 & 7,33 & $S$ & $108,42 \mathrm{abcd}$ \\
\hline Grupo Brilhante Anchieta & 3,67 & 4,83 & 6,17 & 8,33 & $S$ & $106,25 \mathrm{abcd}$ \\
\hline Vagem Branca Maracajá & 3,50 & 4,75 & 5,00 & 7,50 & $S$ & 94,38 abcde \\
\hline FC 2061 & 0,75 & 3,58 & 5,88 & 9,00 & $S$ & 93,83 abcde \\
\hline Preto Brilhoso & 2,00 & 3,17 & 5,17 & 6,29 & $S$ & $79,60 \mathrm{cdef}$ \\
\hline Ligeirinho & 3,50 & 3,50 & 3,92 & 4,00 & $S$ & 67,67 defg \\
\hline FC 2045 & 1,67 & 2,25 & 2,50 & 3,58 & $S$ & 45,75 efg \\
\hline Tipo IAPAR 31 & 0,00 & 0,58 & 0,92 & 4,25 & $S$ & $24,50 \mathrm{fg}$ \\
\hline IAC Carioca Pyatã & 0,00 & 0,00 & 0,83 & 0,67 & $\mathrm{R}$ & $17,88 \mathrm{~g}$ \\
\hline IPR 88 - Uirapuru (Testemunha) & 0,00 & 0,00 & 0,00 & 0,00 & - & $0,00^{*}$ \\
\hline CV (\%) & & & & & & 18,09 \\
\hline
\end{tabular}

${ }^{1}$ Média de quatro repetições; escala de notas de 0 a 9; ${ }^{2}$ Dias após a inoculação; ${ }^{3}$ Reação, aos 28 DAI: suscetibilidade (S) ou resistência (R) ${ }^{4}$ Área abaixo da curva do progresso da murcha-de-curtobacterium. Médias seguidas da mesma letra não diferem ente si na vertical, a 5\% de probabilidade, pelo teste de Tukey. *Dados não incluídos na análise estatística. 
TABELA 4 - Comportamento de cultivares locais de feijoeiro ao isolado FJ 36, de Curtobacterium flaccumfaciens pv. flaccumfaciens (Ensaio 4). Epagri/Cepaf, Chapecó, SC, 2005.

\begin{tabular}{|c|c|c|c|c|c|c|}
\hline \multirow[b]{2}{*}{$\underline{\text { Cultivares }}$} & \multicolumn{4}{|c|}{ Severidade média $^{1}$} & \multirow[b]{2}{*}{ Reação $^{3}$} & \multirow[b]{2}{*}{$\mathbf{A A C P M C}^{4}$} \\
\hline & $10 \mathrm{DAI}^{2}$ & 14 DAI & 21 DAI & 28 DAI & & \\
\hline Carioca Anchieta & 6,42 & 7,17 & 8,50 & 9,00 & $\mathrm{~S}$ & $143,25 \mathrm{a}$ \\
\hline Azulão Guabiju Anchieta & 3,00 & 7,17 & 8,33 & 9,00 & $\mathrm{~S}$ & $135,25 \mathrm{ab}$ \\
\hline Preto Anchieta & 5,75 & 6,67 & 7,92 & 9,00 & $\mathrm{~S}$ & $135,09 \mathrm{ab}$ \\
\hline Preto Precoce Cunha Porã & 5,08 & 6,50 & 8,00 & 9,00 & $\mathrm{~S}$ & $133,42 \mathrm{ab}$ \\
\hline Copinha & 6,42 & 6,75 & 7,33 & 8,83 & $\mathrm{~S}$ & $132,21 \mathrm{ab}$ \\
\hline Azulão Abelardo Luz & 3,67 & 6,00 & 8,33 & 9,00 & $\mathrm{~S}$ & $130,17 \mathrm{ab}$ \\
\hline IPR 88 - Uirapuru & 4,75 & 6,83 & 7,33 & 8,67 & S & $128,75 \mathrm{ab}$ \\
\hline FC 2042 & 4,75 & 5,08 & 8,33 & 9,00 & S & $127,29 \mathrm{ab}$ \\
\hline Serrano Anchieta & 3,25 & 5,83 & 7,58 & 8,67 & S & $122,00 \mathrm{abc}$ \\
\hline Barriga Verde Anchieta & 3,75 & 5,17 & 7,83 & 8,83 & $\mathrm{~S}$ & $121,67 \mathrm{abc}$ \\
\hline Chumbinho Anchieta & 3,58 & 4,17 & 7,83 & 9,00 & S & $116,42 \mathrm{abc}$ \\
\hline Carioca Rosa Canguçu & 2,38 & 4,08 & 8,00 & 8,67 & $\mathrm{~S}$ & $113,54 \mathrm{abc}$ \\
\hline Chumbinho & 3,00 & 5,33 & 6,75 & 8,83 & $\mathrm{~S}$ & $113,50 \mathrm{abc}$ \\
\hline Vagem Rosca & 1,50 & 5,17 & 6,58 & 8,83 & S & $108,42 \mathrm{abc}$ \\
\hline Preto Opaco Anchieta & 2,67 & 4,83 & 6,25 & 9,00 & S & $107,17 \mathrm{abc}$ \\
\hline Vagem Branca & 4,42 & 4,17 & 5,33 & 7,33 & $\mathrm{~S}$ & $94,75 \mathrm{bc}$ \\
\hline Cavalo Vermelho & 1,08 & 2,83 & 5,50 & 6,58 & $\mathrm{~S}$ & $79,29 \mathrm{c}$ \\
\hline Agudo & 1,33 & 2,33 & 4,42 & 8,17 & $\mathrm{~S}$ & $75,00 \mathrm{c}$ \\
\hline IAC Carioca Pyatã & 0,83 & 1,08 & 1,00 & 1,50 & $\mathrm{R}$ & $19,88 \mathrm{~d}$ \\
\hline Vagem Amarela & 1,00 & 1,00 & 1,08 & 1,33 & $\mathrm{R}$ & $19,75 \mathrm{~d}$ \\
\hline IPR 88 - Uirapuru (Testemunha) & 0,00 & 0,00 & 0,00 & 0,00 & - & $0,00^{*}$ \\
\hline $\mathrm{CV}(\%)$ & & & & & & 16,93 \\
\hline
\end{tabular}

${ }^{1}$ Média de quatro repetições; escala de notas de 0 a 9; ${ }^{2}$ Dias após a inoculação; ${ }^{3}$ Reação, aos 28 DAI: suscetibilidade (S) ou resistência (R) ${ }^{4}$ Área abaixo da curva do progresso da murcha-de-curtobacterium. Médias seguidas da mesma letra não diferem ente si na vertical, a $5 \%$ de probabilidade, pelo teste de Tukey. *Dados não incluídos na análise estatística.

Brilhoso, Preto Brilhoso (FC 2036) e IAC Carioca Pyatã emitiram folhas novas, sadias, e reduziram suavemente a nota média de severidade (Tabelas 1 e 2).

Tanto a 'Mouro Piratuba' quanto a cultivar Vagem Amarela foram resistentes até a última avaliação dos sintomas, com AACPMC significativamente semelhante $(\mathrm{P}<0,05)$ àquela apresentada pela 'IAC Carioca Pyatã', padrão de resistência à murcha-de-curtobacterium. Os genótipos Mouro Piratuba e Vagem Amarela foram coletados nos municípios catarinenses de Piratuba e
Anchieta, respectivamente, possuem sementes de coloração preta (Vagem Amarela) e cinza azulado com estrias pretas (Mouro Piratuba) e poderão ser empregados em programas de melhoramento da cultura do feijoeiro que visem lançar cultivares resistentes à $C$. $f$. pv.flaccumfaciens.

Dursun et al. (2002) coletaram 22 acessos de feijoeiro comum e de feijão-de-vagem em diferentes locais da Turquia e avaliaram sua reação perante um isolado de Xanthomonas axonopodis pv. phaseoli. O genótipo AG-7117, de origem desconhecida, foi identificado como fonte de resistência 
ao crestamento bacteriano. Avaliando a reação de cultivares locais de feijoeiro, coletadas em Santa Catarina, perante a infecção natural de $X$. axonopodis pv. phaseoli, em duas épocas de cultivo, Theodoro (2004) verificou que as cultivares "Vermelho Manteiga Estriado" e "FC 2060" apresentaram reação de resistência a $X$. axonopodis pv. phaseoli, sendo indicadas para programas de melhoramento genético da cultura do feijoeiro.

A procura por fontes de resistência à murcha-decurtobacterium tem sido realizada por diversas instituições de pesquisa no Brasil. Rava et al. (2003) identificaram os materiais 'CF 800375', 'Coquinho Enxofre', 'Feijão Baetão', 'Mulatinho MG'e 'Vermelho 1 Epamig' como resistentes à murcha-de-curtobacterium, entre 333 cultivares locais coletadas em sete estados brasileiros. Conforme os autores, esses materiais serão utilizados no programa de melhoramento da Embrapa Arroz e Feijão.

\section{CONCLUSÕES}

Entre as cultivares locais avaliadas, Mouro Piratuba e Vagem Amarela são resistentes ao isolado FJ 36, de C. $f$. pv.flaccumfaciens.

\section{AGRADECIMENTOS}

Aos pesquisadores do programa de melhoramento genético da cultura do feijoeiro da Epagri/Cepaf, por terem fornecido, gentilmente, as sementes das cultivares locais que foram avaliadas no presente trabalho.

\section{REFERÊNCIAS BIBLIOGRÁFICAS}

DURSUN, A.; DONMEZ, F.; SAHIN, F. Identification of resistance to common bacterial blight disease on bean genotypes grown in Turkey. European Journal of Plant Pathology, Dortrecht, v. 108, p. 811-813, 2002.

FLESCH, R. D. Perspectivas da cultura do feijão em Santa Catarina. In: REUNIÃO TÉCNICA CATARINENSE DE MILHO E FEIJÃO, 4., 2003, Lages. Resumos expandidos... Lages: Universidade para o Desenvolvimento do Estado de Santa Catarina, 2003. p. 57-61.

FREYESLEBEN, C. A. Feijão. In: . Síntese anual da agricultura de Santa Catarina 2004-2005. Florianópolis: Epagri/Cepa, 2005. p. 80-104.

HALL, R. Compendium of bean diseases. Saint Paul: APS, $1991.73 \mathrm{p}$.

LEITE JÚNIOR, R. P.; MENEGUIM, L.; BEHLAU, F.;
RODRIGUES, S. R.; BIANCHINI, A. Ocorrência de Curtobacterium flaccumfaciens pv. flaccumfaciens em feijoeiro no Paraná e Santa Catarina. Fitopatologia Brasileira, Fortaleza, v. 26, p. 303, 2001. Suplemento.

MARINGONI, A. C. Comportamento de cultivares de feijoeiro comum à murcha-de-curtobacterium. Fitopatologia Brasileira, Fortaleza, v. 27, n. 2, p. 157-162, 2002.

MARINGONI, A. C.; ROSA, E. F. Ocorrência de Curtobacterium flaccumfaciens pv. flaccumfaciens em feijoeiro no Estado de São Paulo. Summa Phytopathologica, Jaboticabal, v. 23, p. 160-162, 1997.

RAVA, C. A.; COSTA, J. G. C.; FONSECA, J. R.; SALGADO, A. L. Fontes de resistência à antracnose, crestamentobacteriano-comum e murcha-de-curtobacterium em coletas de feijoeiro comum. Revista Ceres, Viçosa, v. 50, n. 292, p. 797-802, 2003.

RODRIGUES, L. S.; ANTUNES, I. F.; TEIXEIRA, M. G.; SILVA, J. B. Divergência genética entre cultivares locais e cultivares melhoradas de feijão. Pesquisa Agropecuária Brasileira, Brasília, v. 37, n. 9, p. 1275-1284, set. 2002.

THEODORO, G. F. Reação de cultivares locais de feijão à Xanthomonas axonopodis pv. phaseoli, em condições de campo. Revista Brasileira de Agrociência, Pelotas, v. 10, n. 3, p. 373-375, 2004.

THEODORO, G. F.; MARINGONI, A. C. Murcha-decurtobacterium no Estado de Santa Catarina e reação de genótipos a Curtobacterium flaccumfaciens pv. flaccumfaciens. Summa Phytopthologica, Botucatu, v. 32, n. 1, p. 34-41, 2006a.

THEODORO, G. F.; MARINGONI, A. C. Efeito de doses de nitrogênio na severidade da murcha-de-curtobacterium em cultivares de feijoeiro comum. Summa Phytopathologica, Botucatu, v. 32, n. 2, p. 131-138, 2006b.

THEODORO, G. F.; MARINGONI, A. C. Efeito de doses de potássio na severidade da murcha-de-curtobacterium em cultivares de feijoeiro comum. Summa Phytopathologica, Botucatu, v. 32, n. 2, p. 139-146, 2006c.

UESUGI, C. H.; FREITAS, M. A.; MENEZES, J. R. Ocorrência de Curtobacterium flaccumfaciens pv. flaccumfaciens em feijoeiro, em Goiás e no Distrito Federal. Fitopatologia Brasileira, Fortaleza, v. 28, n. 3, p. 324, 2003. 